The Draft Proposals contain recognition of the complexity of the task and potential difficulties, and emphasis is given to its limitations. It is hoped that the use of the Treatment Manual will influence future research and follow-up studies on the efficacy of psychiatric treatment. Appendices list in considerable detail the organizational structure of the Commission, definitions for use by the Advisory Committees, categories for the description of every form of therapy, factors that may influence treatment, examples of elements to be included in the 'Narratives', members of the Advisory Committee and budgetary proposals for the Project. It is estimated that the total cost of the five-year project will be about $\$ 500,000$.

\section{The Association for Child Psychology and Psychiatry}

The Association for Child Psychology and Psychiatry is a multidisciplinary scientific society concerned with the study of mental health of children. The membership stands at approximately 2000 and includes psychiatrists, psycho- logists, psychotherapists, social workers, and other professional groups. A monthly programme of meetings is held in London and similar programmes are organized by branches of the Association around the country. There is also a oneday annual conference. The subscription is $\$ 5.00$ per annum and entitles members to attend meetings and to receive the quarterly Journal of Child Psychology and Psychiatry.

Requests for further details and membership enquiries should be addressed to ACPP, 4 Southampton Row, London WC1B 4AB.

\section{West Midlands Institute of Psychotherapy}

The West Midlands Institute of Psychotherapy formally came into being with the holding of its first annual general meeting in January, 1981. Anyone seeking information as to the aims and objectives of the Institute and details of membership should contact the secretary, Dr Gerald Dickens, Uficulme Clinic, Queensbridge Road, Moseley, Birmingham B13 8QD.

\title{
Under Discussion
}

It's quite difficult to keep track of all the College's activities. The organization of the Membership examinations, approval visits, advice to inceptors, reading lists, and so on, most people know about, though they may be less aware of the work done by the Psychiatric Tutors' Sub-Committee, or the Library Committee, or the Audio-Visual Sub-Committee in furthering the educational and training aims of the College. Then there's the furtherance of research, and surveys of the use of psychotherapy, or of ECT or the incidence of hospital deaths. There are not only the quarterly meetings but the specialist sections and special groups which also hold meetings and discussions and sometimes create working parties to examine the aims of that specialty or its role in the NHS or in the life of the community. But Council, or its Public Policy Committee, also create special groups and working parties, quite often in response to Government enquiries, or the setting up of Commissions, or the publication of White Papers. These groups set forth a psychiatric view on confidentiality, or on co-operation between the professions, or on corporal punishment or the mental health of teachers, or on changes required in the Mental Health Act or the laws on adoption, and many more subjects.

The Bulletin tries to keep members informed of all the
College's activities but its editors are dependent on the various working groups and sections telling them from time to time what is going on. Not all the reports and memoranda of evidence can be printed (some of them are very long, some very specialized and of limited interest), but the Bulletin aims to list them all, report many in short or long, and print some in full. In addition, the aim now is to deposit all full reports in the library, where they can be consulted or Xerox copies obtained. The College has recently acquired a word processor and new photocopying equipment and may soon be able to make copies of reports fairly cheaply, and even to produce short runs of small College books.

Communicating is a complex affair nowadays, where mailing costs have to be watched, and the substance of a report may need distributing in two or three different ways to all members in one way, to specialists in another way, to the members of other professions in a third, and to the press in a fourth. This may mean several different writings, choice of reproductive methods according to numbers of copies needed, and knowledge of the different mailing lists the College holds. We have to try harder to make sure everyone is being kept informed.

Printed in Great Britain by Headley Brothers Lid The Invicta Press Ashford Kent and London 